\title{
Editorial
}

\section{The Brazilian Little Way in Academia}

The academic knowledge on Administration is largely developed in North America and Europe WEIRD (Western, Educated, Industrialized, Rich and Democratic) geographic locations. Other locations around the world tend to use WEIRD research standards to identify quality in academy, including standards for publication. It is well known that standards follow us in our lives, both personal and professional, and they are shaped by culture, among other things. WEIRD scholars are the gatekeepers for publishing in more competitive top-tier journals, the ones with high standards for accepting an article for publication, with better quality and higher impact factor. The pressure for publishing in the USA for instance, is relevant both for getting a position in a university, as well to maintain that position over the years.

Is following North American and Europe standards for publication legitimate or should we have our own standards, taking into account our culture and how it shapes Brazilian society? Brazilians have a unique way of doing things that can surprise unaware foreigners: the Brazilian little way (jeitinho), which goes in almost everyday activity. "It is cultural. Jeitinho is a social mechanism widely used in Brazilian society as problem-solving strategy" (Duarte, 2006, p. 509). I have experienced some forms of jeitinho as editor of BAR, luckily not too often.

But is it possible to expect jeitinho among Brazilian scholars? If we can't escape culture, sooner or later one of us in academia will be practicing it in some of our activities: research, teaching or publishing. The Brazilian little way is not necessarily something bad or illegal, it has to do with flexibility or informality in our relationships. But if we are to follow international standards for publication in top journals, are we allowed to use this cultural construct? Considering the conversations I have had with some colleagues over the years, we can find jeitinho in academia in Brazil, for instance in slicing a dissertation into as many articles as possible with our advisees due to the quantity of articles we must publish per year. The dilemma of quality versus quantity, a constant debate in our academy, can lead to practice of jeitinho. Is the path to focus more on quality than quantity in a country with a unique culture like Brazil? 
Sandström and Besselaar (2016) have an intriguing perspective on quantity versus quality of publication when they point that there is

a strong correlation between productivity (number of papers) and impact (number of citations), that also holds for the production of high impact papers: the more papers, the more high impact papers. More specifically, for most fields there are constant or increasing marginal returns. In that sense, increased productivity of the research system is not a perverse effect of output-oriented evaluation systems, but a positive development (p. 12).

They continue: "The increasing popular policy that allows researchers to hand in only their five or so best publications seems in the light of these results counterproductive, as it disadvantages the most productive and best researchers" (p. 12). This is opposed to the slow-science movement,

where the underlying idea is that quality and not quantity should dominate - and that with all the emphasis on numbers of publications, the system has become corrupted. For instance, in the Netherlands the 'science in transition' movement was able to convince the big academic institutions to remove productivity as a criterion from the guidelines for the national research assessment (Sandström \& Besselaar, 2016, p. 2).

Bosquet and Combes (2012) mentioned that "academics who publish more papers and of higher quality are more cited. Academics working in larger co-author teams and who have a larger total coauthor network are also more cited" (p. 23). So, there are two ways to follow in academic life: productivity (the more the better) or quality (slow-science). In Brazil we are following the productivity model and it sometimes leads to the jeitinho in order to publish more and to increase competitiveness for getting funding and scholarships from the government. We can't complain, since authors are not doing something illegal when they publish more, or with more co-authors, or even when they are not the first authors, as long as the standards are being followed and the process is legit.

I work so that BAR follows international standards of quality in publication, and so far we have been successful, thanks to authors, reviewers, and action and associate editors, and despite our Brazilian culture's little way.

The current issue:

The first article Exploring Risk Perception and Degree of Internationalization of Brazilian Small-and-Medium Enterprises by Leandro Rodrigo Canto Bonfim, Gabrielle Ribeiro Rodrigues Silva, Paulo Henrique Müller Prado and Gustavo Abib, investigates managerial risk perception regarding internationalization of small and medium-sized enterprises in the Brazilian context. Results suggest that managers' tolerance for ambiguity is only significant for explaining risk perception for the managers with a preference for a deliberative style and that the investigated Brazilian SMEs presented a higher degree of internationalization even when their managers perceived higher levels of risk.

The second article The Relationship between Sentiment and Risk in Financial Markets by Ana Luiza Paraboni, Marcelo Brutti Righi, Kelmara Mendes Vieira and Vinícius Girardi da Silveira, estimates association coefficients between measures of market sentiment and risk in the U.S., German and Chinese markets. Authors concluded that observations of market sentiment as measured by social media data show a consistent relationship with measures of financial risk.

The third article Sponsor Bias in Pension Fund Administrative Expenses: The Brazilian Experience by Claudio Marcio Pereira da Cunha, investigates sponsor bias, hypothesizing that it may originate from the omission of relevant control variables, specifically variables for location of headquarters and the level of outsourced services. The findings did not support the hypothesis of political bias in administrative expenses of Brazilian closed pension funds, but that the sponsor bias may be driven by characteristics of the pension funds omitted in previous literature.

The fourth article Cultural Meanings and Consumers' Discourses about Their Brand Abandonment by Fillipe Diniz and Maribel Carvalho Suarez, investigates consumers who abandoned 
previously consumed brands in two distinct product categories, soft drinks and automobiles. The analysis illustrates cultural discourses that consumers use to give meanings and socially negotiate their brand abandonment. It presents three types of brand abandonment: (1) contingent, (2) balanced and (3) aversive.

The fifth article Responsible Leadership Research: A Bibliometric Review by Tânia de Matos Gomes Marques, Nuno Rosa Reis and Jorge Gomes, analyzes the use of responsible leadership in management research. Using a sample of 64 articles published in SSCI-indexed journals over 10 years (2006-2016). Six distinct factors have emerged, denoting the groups of studies devoted to the evolution of leadership, transformational leadership, stakeholder theory and leadership, conceptualization and understanding of the topic, and roles of responsible leaders.

We present in this edition the reviewers, Action Editors and Associate Editors that helped us during 2017. BAR could not be possible without your volunteer and relevant work. We hope we can continue to count on you in 2018, always raising the Bar!

To conclude, we include some information for our readers in our first issue of 2018. We have been a member of COPE since 2013. We are listed in various relevant databases, such as SciELO, EBSCO, DOAJ, ProQuest, Redalyc, and many others. We are waiting for the response to our request to be part of JCR. We have a score of 9.6 on MIAR. BAR has always been published in English since its first issue. We started using ScholarOne in 2013. Finally, we have been using iThenticate since 2016. As you can see, we do have international standards and we avoid the Brazilian little way of doing things.

We hope that you will find the articles interesting to help with your learning experience and future research use.

\section{References}

Bosquet, C., \& Combes, P.-P. (2012). Are academics who publish more also more cited? Individual determinants of publication and citation records. Retrieved March 11, 2018, from https://halshs.archives-ouvertes.fr/halshs-00793647

Duarte, F. (2006). Exploring the interpersonal transiction of the Brazilian Jeitinho in Bureaucratic contexts. Organization, 13(4), 509 - 527. https://doi.org/10.1177/1350508406065103

Sandström, U., \& Besselaar, P. van den (2016). Quantity and/or quality? The importance of publishing many papers. PLoS ONE, 11(11), e0166149. https://doi.org/10.1371/journal.pone.0166149

\section{Author Profile}

